\title{
Reward-Based DSM Program for Residential Electrical Loads in Smart Grid
}

\author{
Muthuselvi $\mathrm{G}^{1}$ \\ Research Scholar \\ School of Electrical Engineering \\ Vellore Institute of Technology, Vellore, Tamilnadu, India
}

\author{
Saravanan B ${ }^{2}$ \\ Associate Professor \\ School of Electrical Engineering \\ Vellore Institute of Technology, Vellore, Tamilnadu, India
}

\begin{abstract}
There is a positive attitude towards the use of different strategies for engaging in demand response (DR) programs in energy markets through the innovation and trend of smart grid technologies. In this paper, a reward-based approach is proposed that enhances the involvement of customers in the DR program by assuring the customer's comfort level. Most of the previous works considered limited controllable loads like thermal loads for demand side management (DSM). In this approach thermal and all active electrical loads are considered for the analysis. Comfort indicator is used for the analysis which is an important parameter for measuring comfort of each resident. This technique significantly reduces the utility reward cost and maximizes the user satisfaction level compared with existing approach. The numerical example considered in this work illustrates the fruitfulness of the proposed approach. This problem is formulated as mixed-integer linear programming (MILP) and solved by using CPLEX solver in General Algebraic Modelling Software (GAMS).
\end{abstract}

\section{Keywords-DSM; LSE; RLA; smart grid; reward}

\section{INTRODUCTION}

The solution to demand-supply problems in the power supply system is an efficient DR program. DSM is the customer based DR program in a smart electric grid by changing the regular use of electricity. Demand Side Management (DSM) programs enable load-serving entities (LSE) to manage the electric loads on the user side. Customer interaction and responsiveness are the two critical factors of the DR program. This program requires a collaborative relationship between LSE and consumers to achieve the customer load changes that benefit consumers, LSE and society as a whole. The categories of DSM programs are timebased and incentive/penalty based program. The time-based program depends on electricity prices that vary over time. The incentive program is based on fixed rewards (or) time-varying incentives. These programs play a significant role in reducing demand in peak periods. With the introduction of the new reward-based DR program consumers are encouraged to reduce their loads during peak hours.

The DR program classification is as shown in Fig. 1. The dynamic pricing schemes like Real Time Pricing (RTP), Time Block Pricing (TBP), Critical Peak Pricing (CPP), and Time of Use (ToU) are commonly used in the DR program to lower peak demand by encouraging the users. In [1], the author proposed a Home Energy Management System (HEMS) with price-based DR programs for reducing the consumer's electricity cost by transferring the ON peak load usage to the OFF peak periods. During peak hours of the day, utilities have control over Direct Load Control (DLC) to shed the load of the consumer. The utility commonly control loads of the customer remotely in Interruptible / Curtailable Service (CS) to achieve the required load reduction level. Several researchers [2-9] suggested the implementation of optimal DR scheduling via incentives. Demand Bidding (DB) is a process that encourages consumers to involve actively in electricity usage trading. It offers incentives for accepting to reduce their electricity usage during peak load periods [10], [11]. Incentive-based DR programs is the most powerful tool for handling peak load and attract more consumers in the DR program. There are several methods and strategies explored to reduce peak demand, utility reward cost and consumer electricity costs. Existing methods have less concentration in the improvement of the participation factor of the consumer in the DR program.

DR program reduces the electricity cost of consumers by motivating them to use less power consumption in high-priced periods [12] and more power consumption in low-priced periods. The author demonstrated the DR program of residential areas by encouraging customers to voluntarily minimize their daily energy use by scheduling available resources in [13].

Optimization approaches to modify the customer's load curve in response to the changes in the electricity cost through incentive is analyzed in [14]. In this approach complexity faced on customer satisfaction level is analyzed at minimal percentile [15]. Previous studies focused mainly on the minimization cost at the consumer level and not dealt with the revenue cost of utility received from the grid operator [16], [17], and [19]. Smart Home Energy Management Systems (HEMS) uses real-time information under various schemes to manage loads of residential communities. Price based HEMS are discussed [23-25] under restricted controllable appliances. In [21], the author formulated an optimization approach as a Multi-Constrained Mixed-Integer Problem (MCMIP) that schedules the controllable appliances based on consumer preferences. A researcher proposed an Adaptive Differential Evolution Algorithm (ADEA) to find the optimal schedule of appliances in the sectors like residential, industrial, and commercial [22]. In this work, peak load minimization and reduction in consumer's electricity bills are considered as the objectives. 


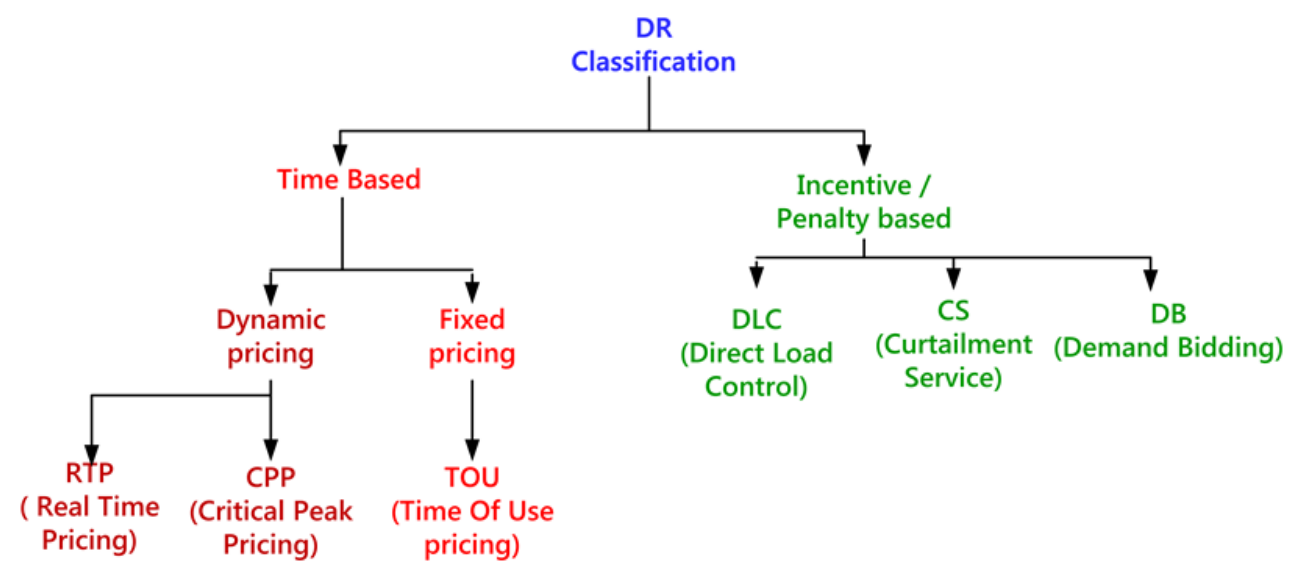

Fig. 1. Types of DR Programs.

The impacts, as mentioned earlier in existing methods, are rectified in this proposed approach. In this approach, controllable (electric vehicle, clothes dryer, dish washer, pool pump, energy storage), thermal and all active electrical loads are considered for the analysis. LSE sends the preferred demand reduction request (PDRR) to all the Residential Load Aggregator (RLA). Then RLA generates the optimal scheduling of appliances based on preferred demand reduction limits (DRL) and the willingness to compromise the load demand of all the residents. Customers are granted a reward depending on the participation in the DR program. New reward rates and demand reduction requests are informed to each consumer through home energy communication network port.

The remaining section of this article is structured as follows. Section 2 discusses the modelling structure of various appliances. Section 3 illustrates the reward structure used in the analysis. Section 4 with the problem formulation for the objectives and constraints. Section 5 deals with the case study considered in this approach. Finally, Sections 5 and 6 discuss the results and conclusion, respectively.

\section{OVERVIEW OF APPLIANCES MODELling}

This section describes the modelling of residential loads. Modelling parameters for appliances are considered from [18] and [20]. Controllable/Shiftable and uncontrollable/nonshiftable are the two classifications of appliances in the residential sector. Uncontrollable appliances have fixed power and time of operation. Controllable devices run within the desired working time based on their power consumption and time i.e. they may allow the operating schedule to be changed.

\section{A. Controllable Loads}

1) EWH Model: When the current temperature exceeds the setpoint value, the condition of EWH is OFF. If the current temperature is below the minimum temperature required by EWH, then the status is ON. If the temperature is between the minimum required temperature and the setpoint temperature, then the EWH state follows the status of the previous time are shown in (1). The power consumption is calculated using equation (2).
$S_{E W H, h, t}=\left\{\begin{aligned} & 0, T_{E W H, h, t}>T_{E W H, s} \\ & 1, T_{E W H, h, t}<T_{E W H, r} \\ & S_{E W H, h, t-1}, T_{E W H, r} \leq T_{E W H, h, t} \leq T_{E W H, s}\end{aligned}\right.$

$p_{E W H, h, t}=P_{E W H} \cdot S_{E W H, h, t}$

2) AC Model: It is one of the significant thermal controlled residential appliances. When the room temperature is conquer $\left(T_{A C, s p}+T_{A C, D B}\right)$, $\mathrm{AC}$ is $\mathrm{ON}$. When the room temperature is below $\left(T_{A C, s p}-T_{A C, D B}\right)$ the status of $\mathrm{AC}$ is OFF. Otherwise, it follows the previous status. If the state of $\mathrm{AC}$ is $\mathrm{ON}$, the rated power is consumed. In the OFF state, no power will be consumed. The consumed power of AC for resident ' $h$ ' at time ' $t$ ' is illustrated as follows:

$$
\begin{aligned}
& S_{A C, h, t}= \\
& \left\{\begin{array}{c}
0, T_{A C, h, t}<T_{A C, s p}-T_{A C, D B} \\
1, T_{A C, h, t}>T_{A C, s p}+T_{A C, D B} \\
S_{A C, h, t-1}, T_{A C, s p}-T_{A C, D B} \leq T_{A C, h, t} \leq T_{A C, s p}+T_{A C, D B}
\end{array}\right. \\
& p_{A C, h, t}=P_{A C} \cdot S_{A C, h, t}
\end{aligned}
$$

3) Clothes dryer model: Equation (5) details the ON/OFF status of the CD. The state is ON when the total accumulated time is lower than the needed time to complete the job. The state is OFF when the accumulated time higher than or equal to the time necessary to initiate the job. The expression for power consumption of CD is in equation (6).

$S_{\mathrm{CD}, \mathrm{h}, t}=\left\{\begin{array}{l}0, T_{\mathrm{CD}, a c c} \geq T_{\mathrm{CD}, r} \\ 1, T_{\mathrm{CD}, a c c}<T_{\mathrm{CD}, r}\end{array}\right.$

$p_{\mathrm{CD}, h, t}=P_{\mathrm{CD}} \cdot S_{\mathrm{CD}, h, t}$

4) Electric vehicle model: The State-of-Charging (SoC) of the battery at a time ' $\mathrm{t}$ ' is the ratio of remaining $E V_{\text {rem }}(t)$ or residual capacity at that time to the maximum battery capacity, as shown in equation (7). ON/OFF status of EV is illustrated in equation (8). It is $\mathrm{ON}$, when the SoC is less than the maximum capacity and is OFF, when the SoC is greater than or equal to the maximum state of charge. The power consumption of EV is calculated using equation (9). 
$\operatorname{SOC}(t)=\frac{E V_{\text {rem }}(t)}{E V_{\max }}$

$S_{\mathrm{EV}, h, t}=\left\{\begin{array}{l}0, S O C_{h, t} \geq S O C_{\text {max }} \\ 1, S O C_{h, t}<S O C_{\text {max }}\end{array}\right.$

$p_{\mathrm{EV}, h, t}=P_{\mathrm{EV}} \cdot S_{E V, h, t}$

5) Dishwasher model: The representation of the state of Dish Washer (DW) is, as shown in equation (10). The status of DW is ON when the cumulative ON time is lower than the needed ON time to complete dishwashing. It is OFF when the overall ON time greater than or equal to the needed ON time to finish that cycle. Equation (11) represents the power consumption of DW.

$S_{\mathrm{DW}, h, t}=\left\{\begin{array}{l}0, T_{\mathrm{DW}, a c c} \geq T_{\mathrm{DW}, r} \\ 1, T_{\mathrm{DW}, a c c}<T_{\mathrm{DW}, r}\end{array}\right.$

$p_{D W, h, t}=P_{D W} \cdot S_{\mathrm{DW}, h, t}$

6) Cloth washer model: Equation (12) illustrates the status of Cloth Washer (CW). The condition of $\mathrm{CW}$ is $\mathrm{ON}$ when the cumulative $\mathrm{ON}$ time is lower than the needed time to complete the washing job. The status is OFF when the overall ON time greater than or equal to the needed $\mathrm{ON}$ time. The power consumption of $\mathrm{CW}$ is calculated using equation (13).

$S_{C W, h, t}=\left\{\begin{array}{l}0, T_{C W, a c c} \geq T_{C W, r} \\ 1, T_{C W, a c c}<T_{C W, r}\end{array}\right.$

$p_{C W, h, t}=P_{C W} \cdot S_{C W, h, t}$

7) Pool pump model: The status of Pool Pump (PP) is represented in equation (14). The state is ON when the time taken for the operation is less than the desired total operating time and is OFF when its operating time exceeds the expected total running time. Power consumption of PP is obtained using equation (15).

$S_{P P, h, t}=\left\{\begin{array}{l}0, T_{\mathrm{PP}, a c c} \geq T_{P P, r} \\ 1, T_{\mathrm{PP}, a c c}<T_{\mathrm{PP}, r}\end{array}\right.$

$p_{P P, h, t}=P_{\mathrm{PP}} \cdot S_{\mathrm{PP}, h, t}$

\section{B. Uncontrollable Loads}

Uncontrollable loads are loads that fix their mode operation in time and power consumption. The loads, including TV, computer, lighting loads, fan, and refrigerator, are examples considered in this category for the analysis. Each appliance's power ratings are regarded as of [19].

\section{REWARD-BASED DR FRAMEWORK}

\section{A. Reward Rate Structure}

In this proposed study, the reward-based DR model is formulated. In this framework, LSE sends the preferred demand reduction request to all RLA. Then RLA generates the optimal scheduling of appliances based on preferred demand reduction limits (DRL) and the willingness to compromise the load demand of all the residents are generated by RLA. Customers are granted a reward depending on the participation in the DR program. The reward rate Rw2 is given to the houses that are willing to compromise their demand during the PDRR event. Rw3 reward rate is awarded to the houses those who are not willing to compromise their demand during the PDRR event. But the Rw3 reward rate will be used only during the emergency (or) rare events. The choice between Rw1 and Rw2 plays a significant role in the optimization problem.

Table I represents the different reward-based rate structures. Here is a simple example that explains the reward rate for the residents based on their willingness to compromise and preferred demand reduction limits. In this, rewards Rw1, Rw2, and Rw3 are considered as 20, 40, 60 cents / kW.

Here this include three houses A, B, and C. The preferred Demand Reduction Limits (DRL) of each resident is as shown in Table I. The total demand for all the residents is $35.6 \mathrm{~kW}$. Assume LSE expects $30 \%$ of load reduction from RLAs. So RLA makes the optimal strategies that satisfy the requisition, which is given by LSE. In this example, $11.7 \mathrm{~kW}$ is expecting to reduce during that particular period. Depending on the DRL desired by each house, the LSE specification that met with 8.3 $\mathrm{kW}$ (total power minus DRL). Houses A and C are agreed to compromise their demands for the remaining $\mathrm{kW}$. So the Rw2 reward rate is given to houses $\mathrm{A}$ and $\mathrm{C}$ because of their comfort index, which is higher than 1.House B is getting Rw1 reward rate because the willingness to compromise is ' 0 '. An emergency is a rare occurrence case. Reward rate Rw3 is provided, if the compromise is equal to ' 0 ' and CI value is higher than 1. In this case, house ' $\mathrm{B}$ ' will handle the emergency case and get the Rw3 reward rate.

\section{B. Comfort Index}

The optimal scheduling of appliances of all the residents and the participation of customers depends upon the factor of CI. The design of the CI considers both thermal and other active appliances participating in the DR program. If the value of the CI is higher than ' 1 ', the residents are in an uncomfortable zone. When the CI is less than or equal to ' 1 ', the residents are in a comfortable area.

TABLE I. EXAMPLE OF REWARD RATE STRUCTURE

\begin{tabular}{|c|c|c|c|c|c|c|}
\hline \multirow{2}{*}{ House } & \multirow{2}{*}{ Power(kW) } & \multirow{2}{*}{ Demand reduction limit $(\mathrm{kW})$} & \multirow{2}{*}{ Compromise (1-yes,0-No) } & \multicolumn{3}{|c|}{ Reward (\$) } \\
\hline & & & & Normal & Occasional & Emergency \\
\hline $\mathbf{A}$ & 14.3 & 10.6 & 1 & Rw1 & Rw2 & - \\
\hline B & 12.8 & 9.5 & 0 & Rw1 & - & Rw3 \\
\hline $\mathbf{C}$ & 8.5 & 7.2 & 1 & Rw1 & Rw2 & - \\
\hline
\end{tabular}


The normalized value of $\mathrm{CI}$ is calculated using the equation (16).

$C I_{n}=n 1 C I_{H, h, t}+n 2 C I_{R, h, t}$

Where, $C I_{H, h, t}=C I_{A C, h, t}+C I_{W H, h, t}$, CI of thermal appliances.

$C I_{R, h, t}=\mathrm{CI}$ of remaining active appliances

Where $n 1$ and $n 2$ are weight factors and $(n 1+n 2)=1$.

The CI of AC is calculated as in equation (17),

$C I_{A C, h, t}=\left|\frac{2 T_{A C, h, t}-T_{A C, L o, h}-T_{A C, H i, h}}{T_{A C, H i, h}-T_{A C, L o, h}}\right|$

The CI of EWH is illustrated as in equation (18),

$C I_{W H, h, t}=\left|\frac{2 T_{W H, h, t}-T_{W H, L o, h}-T_{W H, H i, h}}{T_{W H, H i, h}-T_{W H, L o, h}}\right|$

The CI of all the remaining active controllable appliances is as shown below,

$C I_{R, h, t}=\left|\frac{T N A_{h}-T A A_{h}}{T N A_{h}-T R A_{h}}\right|$ ' $h$ '.

Where, $T N A_{h}=$ Number of active appliances in resident

$T A A_{h}=$ Number of allowed appliances to $\mathrm{ON}$ in resident ' $h$ '. $T R A_{h}=$ Total number of requested appliances to $\mathrm{ON}$ in resident ' $h$ '.

\section{PROBLEM Formulation}

The relation between reward rate and CI is as follows:

$R W R_{h, t}=\left\{\begin{array}{c}\mathrm{Rw} 1, \text { if } C I \leq 1 \\ \mathrm{Rw} 2, \text { if } C I>1 \text { and compromise }=1 \\ \mathrm{Rw} 3, \text { if } C I>1 \text { and compromise }=0\end{array}\right.$

From equation (20), if the CI value is less than or equal to '1' (i.e. Customer Satisfaction), reward 'Rw1' will be given. If the CI is more than ' 1 ' (i.e. Customer Dissatisfaction) and is willing to reduce demand, consumers are rewarded with 'Rw2'. If the consumer is not ready to compromise, the demand and the reward rate is ' $\mathrm{Rw} 3$ ' is provided to encourage them for active participation. It is a rate which is given during emergency but it is a rare case. These reward structures are used to attract the non-participant and not compromised customers to involve in the DR program.

$$
\begin{aligned}
& R W R_{h, t}=\mathrm{Rw}_{1} b_{h, t}+\mathrm{Rw}_{2}\left(1-b_{h, t}\right) \operatorname{comp}_{h}+\mathrm{Rw}_{3}(1- \\
& \left.b_{h, t}\right)\left(1-\operatorname{comp}_{h}\right)
\end{aligned}
$$

Where, $b_{h, t}$ is a binary variable and $\operatorname{comp}_{h}$ is a compromise for the house ' $h$ '.

By considering the following objective function and constraints, the optimization problem is formulated. The primary objective of this proposed approach is to reduce the utility reward costs and CI. While reducing CI, the satisfaction level of the user's comfort will increase. The objective function is as shown in equation (22).

$\mathrm{C}=\min \sum_{h=1}^{H} R W_{h, t}+k \cdot \sum_{h=1}^{H} C I_{h}$
With the following constraints:

$\sum_{h=1}^{H} C D R_{h, t} \geq P D R R_{t}$

$-B b_{h, t}<\left(D R L-P_{a, h, t}\right) \leq B\left(1-b_{h, t}\right)$

$P_{a, h, t}=\sum_{n=1}^{N} P_{h, n, t} \cdot S_{h, n, t}$

$R W_{h, t}=\left(P_{T, h, t}-P_{a, h, t}\right) \cdot R W R_{h, t}$

Where, $\mathrm{k}$ is the CI weight factor, $C D R_{h, t}$ is the Consumer Demand Reduction of the resident ' $h$ ' $(\mathrm{kW})$ at time't' and B is a positive constant, $S_{h, n, t}$ is the status of the appliance (1 or 0 ). Equation (23) represents the total demand reduction of all the residents should be higher than or equal to PDRR. It is not possible to achieve a reduction in demand beyond the resident's total power consumption and is expressed in equation (24). The overall power consumption is corresponding to the sum of power consumption of active appliances in all the residents, as shown in equation (25). The reward rate for each resident is calculated using equation (26). Hence, this problem is formulated as mixed-integer linear programming (MILP).

\section{OPTIMAL SOLUTION APPROACH}

\section{A. Conventional Approach}

In [2], the concept of $\mathrm{CI}$ is used for measuring consumer comfort level by considering the thermal appliances like AC and EWH alone. BONMIN solver in GAMS is used to verify the performance of the approach. Two DRR schemes such as $30 \%$ and $60 \%$ are performed and validation is done only for AC.

\section{B. Proposed Approach}

The above problem statement is the mixed of continuous variable $P_{a, h, t}$, discrete variable (reward rate) and binary variable $b_{h, t}$. Therefore it can be modeled as MILP.

By substituting equation (21) and (26) in (22), the new objective function is obtained as follows in equation (27).

$$
\mathrm{C}_{N e w}=\min _{P_{a, h, t}}\left\{\begin{array}{c}
P_{T, h, t}\left[\left(\mathbf{R} \mathbf{w}_{1}-\mathbf{R} \mathbf{w}_{3}\right) b_{h, t}+\mathbf{R} \mathbf{w}_{3}\right]- \\
B_{n e w, i, t}\left(\mathbf{R} \mathbf{w}_{1}-\mathbf{R} \mathbf{w}_{3}\right)-P_{a, h, t} \mathbf{R} \mathbf{w}_{3}+k C I+ \\
\left(P_{T, h, t}-P_{a, h, t}\right)\left[\left(\mathbf{R w}_{2}-\mathbf{R} \mathbf{w}_{3}\right)\left(1-b_{h, t}\right) \operatorname{comp}_{h}\right]
\end{array}\right\}
$$

Subject to the following constraint (28) along with the constraints (23), (24), (25) and (26).

$0 \leq B_{\text {new }, i, t} \leq P_{T, h, t} b_{h, t}$

Where, $B_{\text {new } i, t}=P_{a, h, t} b_{h, t}$.In this approach, as $b_{h, t}$ is considered as binary variable $B_{n e w, i, t}$ is zero if $b_{h, t}=0$ otherwise $B_{\text {new }, i, t}=P_{a, h, t}\left(b_{h, t}=1\right)$.

Then the utility reward cost and average comfort for each house are calculated. This MILP for reducing the utility reward costs and CI, which is guaranteed the finding global optimum operation work has been solved by using CPLEX solver in General Algebraic Modelling Software(GAMS). 


\section{Case Studies}

The proposed DSM strategy for the residential consumer is performed on 10, and 500 residents and input data are taken from [2]. The test system considers thermal, controllable and other active appliances that are participated during the DR program. The load data of the 10 residents are recognized for this analysis as given in Table II. The total demand of 10 residents is $157.8 \mathrm{~kW}$. Table III shows the total demand reduction of 10 residents for various CDR during peak hours. DR program of each resident is done based on user-preferred load and DRL. DRL is the threshold value for demand reduction and decided by each user. Compromise ' 1 ' represents the resident is willing to compromise their demand during the peak hours. Compromise ' 0 ' represents the resident is not ready to reduce their demand.

Table IV shows the average percentage of comfort and reward for various PDRR. In this case study Rw1, Rw2, and Rw3 are considered as 20, 40, 60 cents / $\mathrm{kW}$ (5 min). The comfort percentage is the measure of the number of times the power consumption of the residents is within the user preferred power range. The time duration taken for implementing each PDRR is 5 minutes. The reward rate and comfort percentage of each PDRR for 10 residents are explained below. In this analysis, six PDRR are discussed like $10 \%, 20 \%, 30 \%, 40 \%, 50 \%$ and $60 \%$.

- PDRR\#1 with $16 \mathrm{~kW} / 20 \mathrm{~min}$ (10\%): RLA receives a request of $16 \mathrm{~kW}$ for the time length of 20 minutes from LSE. Ten residents' total demand is $157.8 \mathrm{~kW}$. Approximately $10 \%$ of the load from the total demand is decreased. All residents are within their reduction limit of preferred demand. Therefore, for all residents, the percentage of comfort is $100 \%$ and with the Rw1 reward. According to their lower power utilization and a wide range of demand reduction limits, Resident 3 gets more reward. Resident 2 does not earn any reward because of their lower comfortable power range.

- PDRR\#2 with $32 \mathrm{~kW} / 20 \mathrm{~min}$ (20\%): RLA receives a request of $32 \mathrm{~kW}$ from LSE for 20 minutes. Approximately $20 \%$ of the load from the total demand is reduced. All residents are within their preferred demand reduction limits. Therefore the percentage of comfort is $100 \%$ for all the residents and with the reward of Rw1. Resident 7 procured more rewards due to their less power utilization and a wide range of demand reduction limits.

- PDRR\#3 with 47kW/20min (30\%): RLA receives a request of $47 \mathrm{~kW}$ for 20 minutes from LSE. Approximately 30 percent of the load is decreased from total demand. All residents are within their required demand reduction limit. The rate of comfort for all residents is therefore $100 \%$, and the rate of reward is Rw1. Resident 7 received more rewards because of their lower power consumption and a wide range of reduction in demand.

- PDRR\#4 with $63 \mathrm{~kW} / 20 \mathrm{~min}$ (40\%): RLA receives a request of $63 \mathrm{~kW}$ for the time length of 20 minutes from LSE. The total demand reduction of 10 residents is approximately $40 \%$ of total demand. All the residents are within their preferred demand reduction limits. Therefore the percentage of comfort is $100 \%$ for all the residents and with the reward of Rw1. Resident 5 has earned more reward because of their reduced power use and a wide range of reduced demand.

- PDRR\#5 with $75 \mathrm{~kW} / 20 \mathrm{~min}$ (50\%): RLA receives a request of $79 \mathrm{~kW}$ for the time length of 20 minutes from LSE. Approximately $50 \%$ of the load is reduced from total demand. All the residents are within their preferred demand reduction limits. Therefore the percentage of comfort is $100 \%$ for all the residents excludes and with the reward of Rw1 and Rw2. Resident 7 procured more reward due to their less power utilization and a wide range of demand reduction limits.

- PDRR\#6 with 95kW/20min (60\%): RLA receives a request for the time length of 20 minutes from LSE of $95 \mathrm{~kW}$. The demand reduction of $60 \%$ is achieved from total demand. Some of the residents are within their preferred demand reduction limits. The level of comfort for all residents is therefore $100 \%$, except residents 1,5 , and 9 with a reward rate of Rw1 and Rw2. Resident 1 procured more rewards due to their less power utilization and a wide range of demand reduction limits. The reward cost of utilities will also be increased while the PDRR is increasing. During an emergency, the affected houses can receive reward rate Rw3.

TABLE II. TOTAL LOAD DATA OF THE 10 RESIDENTS

\begin{tabular}{|c|c|c|c|c|c|c|c|c|c|}
\hline \multirow{2}{*}{ Resident } & \multicolumn{7}{|c|}{ Controllable devices $(\mathrm{kW})$} & \multirow{2}{*}{$\begin{array}{l}\text { Uncontrollable } \\
\text { Devices (kW) }\end{array}$} & \multirow{2}{*}{ Total power $(\mathrm{kW})$} \\
\hline & $\mathbf{A C}$ & EWH & CD & DW & EV & CW & PP & & \\
\hline 1 & 1.4 & 4.0 & 3.4 & 2.9 & 4.0 & 1.3 & 1.2 & 1.1 & 19.3 \\
\hline 2 & 1.2 & 3.9 & 3.7 & 2.7 & 0 & 0.9 & 1.3 & 1.3 & 15.0 \\
\hline 3 & 1.5 & 3.5 & 3.8 & 3.0 & 3.8 & 1.1 & 1.4 & 1.3 & 19.4 \\
\hline 4 & 1.6 & 3.8 & 0 & 2.6 & 0 & 1.2 & 1.5 & 1.1 & 11.8 \\
\hline 5 & 1.3 & 3.1 & 3.1 & 0 & 3.6 & 1.0 & 1.1 & 1.4 & 14.6 \\
\hline 6 & 1.2 & 3.4 & 3.5 & 2.8 & 0 & 1.3 & 1.2 & 1.2 & 14.6 \\
\hline 7 & 1.1 & 3.9 & 3.7 & 0 & 3.8 & 1.2 & 1.3 & 1.5 & 16.5 \\
\hline 8 & 1.5 & 3.8 & 0 & 2.9 & 4.0 & 0.9 & 1.4 & 1.7 & 16.2 \\
\hline 9 & 1.5 & 4.0 & 3.3 & 2.6 & 0 & 1.1 & 1.5 & 1.1 & 15.1 \\
\hline 10 & 1.3 & 3.2 & 3.2 & 0 & 3.6 & 1.2 & 1.6 & 1.2 & 15.3 \\
\hline
\end{tabular}


TABLE III. TOTAL CDR OF 10 RESIDENTS

\begin{tabular}{|c|c|c|c|c|c|c|c|c|c|}
\hline \multirow{2}{*}{ Resident } & \multirow{2}{*}{ Total power $(\mathrm{kW})$} & \multirow{2}{*}{ DRL (kW) } & \multirow{2}{*}{$\begin{array}{l}\text { Compromise } \\
(\text { Yes }=1, \text { No=0) }\end{array}$} & \multicolumn{6}{|c|}{ CDR (kW) } \\
\hline & & & & $10 \%$ & $20 \%$ & $30 \%$ & $40 \%$ & $50 \%$ & $60 \%$ \\
\hline 1 & 19.3 & 11.4 & 1 & 18.3 & 16.2 & 14.1 & 11.4 & 7.9 & 5.6 \\
\hline 2 & 15 & 7.9 & 0 & 14.5 & 12.4 & 10.7 & 7.9 & 7.9 & 7.9 \\
\hline 3 & 19.4 & 12.8 & 1 & 16.1 & 15.7 & 14.5 & 12.8 & 8.1 & 7.1 \\
\hline 4 & 11.8 & 7 & 0 & 11.1 & 9.5 & 8.4 & 7 & 7 & 4.5 \\
\hline 5 & 14.6 & 7.1 & 1 & 13.5 & 12.8 & 9.7 & 7.1 & 8.6 & 5.1 \\
\hline 6 & 14.6 & 10.8 & 0 & 12.4 & 11.5 & 11 & 10.8 & 10.8 & 6.5 \\
\hline 7 & 16.5 & 10.6 & 1 & 14.8 & 12.8 & 10.9 & 10.6 & 4.5 & 7.1 \\
\hline 8 & 16.2 & 9.2 & 0 & 14.1 & 10.9 & 11.2 & 9.2 & 9.2 & 9.2 \\
\hline 9 & 15.1 & 9.7 & 1 & 13.7 & 12.1 & 9.9 & 9.7 & 6.4 & 5.4 \\
\hline 10 & 15.3 & 6 & 0 & 13.5 & 12.3 & 10.1 & 8.5 & 8.5 & 4.7 \\
\hline
\end{tabular}

TABLE IV. PERCENTAGE OF COMFORT AND REWARD FOR VARIOUS PDRR

\begin{tabular}{|c|c|c|c|c|c|c|c|c|c|c|c|c|}
\hline \multirow[b]{2}{*}{ Resident } & \multicolumn{2}{|l|}{$10 \%$} & \multicolumn{2}{|l|}{$20 \%$} & \multicolumn{2}{|l|}{$30 \%$} & \multicolumn{2}{|l|}{$40 \%$} & \multicolumn{2}{|l|}{$\mathbf{5 0 \%}$} & \multicolumn{2}{|l|}{$60 \%$} \\
\hline & $\begin{array}{l}\text { Avg. } \\
\text { Comfort } \\
\text { (\%) }\end{array}$ & $\begin{array}{l}\text { Reward } \\
\text { (\$) }\end{array}$ & $\begin{array}{l}\text { Avg. } \\
\text { Comfort } \\
\text { (\%) }\end{array}$ & $\begin{array}{l}\text { Reward } \\
(\$)\end{array}$ & $\begin{array}{l}\text { Avg. } \\
\text { Comfort } \\
(\%)\end{array}$ & $\begin{array}{l}\text { Reward } \\
(\$)\end{array}$ & $\begin{array}{l}\text { Avg. } \\
\text { Comfort } \\
(\%)\end{array}$ & $\begin{array}{l}\text { Reward } \\
(\$)\end{array}$ & $\begin{array}{l}\text { Avg. } \\
\text { Comfort } \\
(\%)\end{array}$ & $\begin{array}{l}\text { Reward } \\
(\$)\end{array}$ & $\begin{array}{l}\text { Avg. } \\
\text { Comfort } \\
(\%)\end{array}$ & $\begin{array}{l}\text { Reward } \\
(\$)\end{array}$ \\
\hline 1 & 100 & 0.2 & 100 & 0.92 & 100 & 2.07 & 100 & 3.16 & 100 & 9.12 & 75 & 13.97 \\
\hline 2 & 100 & 0 & 100 & 0.78 & 100 & 1.73 & 100 & 2.84 & 100 & 5.68 & 100 & 7.24 \\
\hline 3 & 100 & 0.67 & 100 & 1.11 & 100 & 1.94 & 100 & 2.64 & 100 & 9.04 & 100 & 12.54 \\
\hline 4 & 100 & 0.14 & 100 & 0.69 & 100 & 1.38 & 100 & 1.92 & 100 & 3.84 & 100 & 7.45 \\
\hline 5 & 100 & 0.22 & 100 & 0.54 & 100 & 1.96 & 100 & 4.50 & 100 & 4.80 & 75 & 9.69 \\
\hline 6 & 100 & 0.44 & 100 & 0.93 & 100 & 1.44 & 100 & 1.52 & 100 & 3.04 & 100 & 8.26 \\
\hline 7 & 100 & 0.34 & 100 & 1.71 & 100 & 2.24 & 100 & 2.36 & 75 & 12.24 & 100 & 9.58 \\
\hline 8 & 100 & 0.42 & 100 & 0.99 & 100 & 2.0 & 100 & 2.80 & 100 & 5.60 & 100 & 7.14 \\
\hline 9 & 100 & 0.28 & 100 & 0.90 & 100 & 3.12 & 100 & 2.16 & 100 & 6.96 & 75 & 9.89 \\
\hline 10 & 100 & 0.36 & 100 & 0.89 & 100 & 2.08 & 100 & 2.72 & 100 & 5.44 & 100 & 10.81 \\
\hline
\end{tabular}

\section{RESUlT AND DISCUSSION}

\section{A. 10 Resident System}

In the current framework, thermal controlled devices EWH and $\mathrm{AC}$ are considered to determine the level of comfort. In this method, all the device status in residents is taken into account. The simulation result shows the Percentage Average Comfort (PAC) and Utility Reward Cost (URC). Fig. 2(a, b) demonstrates the effect of URC when considering different amounts of reduction in demand and time for a 10 resident system for existing and proposed method. Compared to the existing method [2], the simulation shows reduced URC for various PDRR during the time length. Fig. 3(a, b) shows PAC for existing and proposed method .PAC is same in both the methods up to $40 \%$ of PDRR for different time length. Some residents may be less comfortable while increasing the PDRR above $40 \%$. The affected residents may get the reward rate Rw2. This method provides a higher level of comfort above $40 \%$ of PDRR. For the existing and proposed method, the PAC and average URC for 10 resident systems are as shown in Table V.

It is observed that the performance for $60 \%$ DRL, the average reward cost URC for existing, and these proposed methods are \$346.44 and \$207.82. PAC for existing and the proposed method are $52.5 \%$ and $88 \%$.

\section{B. 500 Resident System}

The data of large systems are taken from [2]. In this analysis 500 resident system is considered. Fig. 4(a, b) compares the behaviour of PAC of proposed method along with existing method for different time length and PDRR. While increasing the PDRR for an increasing time length there is a significant reduction of PAC. But when compared to the existing method the PAC is $60 \%$ higher. This leads to the reduction of overall utility reward cost for performing the entire PDRR program. Fig. 5(a, b) shows the effect of URC for different percentage of reduction in demand and time length for 500 resident system. For the current and proposed method, the PAC and URC for 500 resident systems are obtained as in Table VI. It is observed that for $80 \%$ PDRR, the reward cost URC for existing, and these proposed methods are $\$ 13500$ and $\$ 10700$. PAC for existing and the proposed method are $18.5 \%$ and $78.5 \%$. The simulation result shows that this approach minimizes the utility reward cost significantly and increases the percentage of average comfort compared to the existing method.

TABLE V. RESULT COMPARISON FOR 10 RESIDENTS

\begin{tabular}{|l|l|l|}
\hline Approach & $\begin{array}{l}\text { Percentage of average Comfort } \\
\text { (PAC) (\%) }\end{array}$ & $\begin{array}{l}\text { Utility reward cost } \\
\text { (URC) (\$) }\end{array}$ \\
\hline Existing[2] & 52.5 & 346.44 \\
\hline Proposed & 88 & 207.82 \\
\hline
\end{tabular}




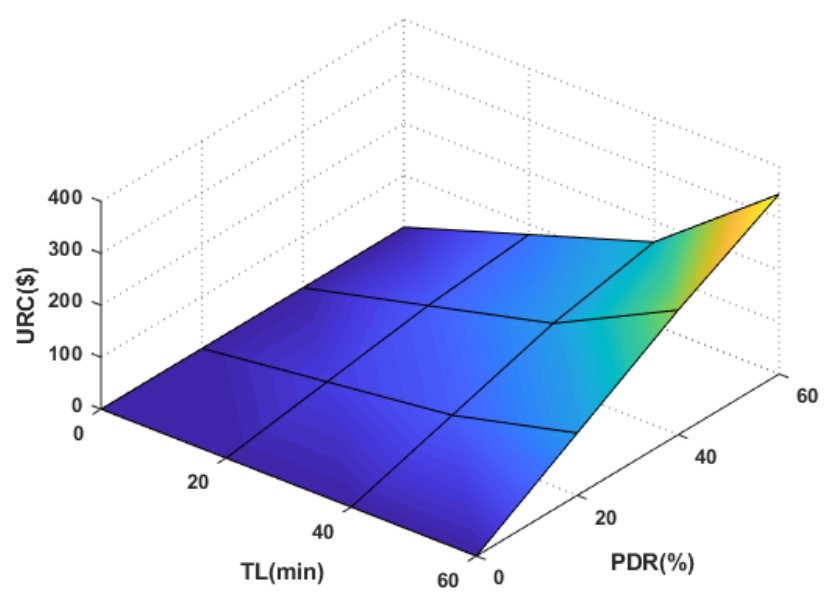

(a) Existing Method.

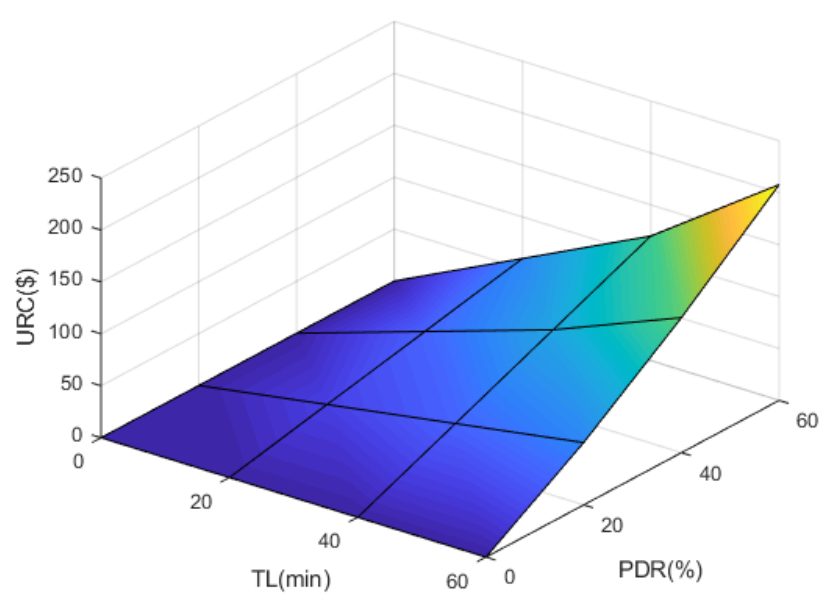

(b) Proposed Reward Method.

Fig. 2. Result of utility Reward Cost for 10 Residents System.

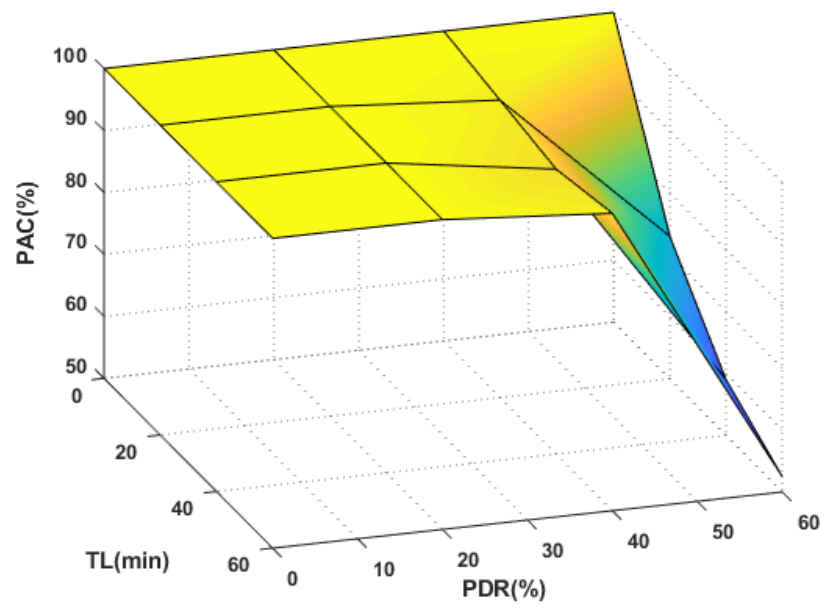

(a) Existing Method.

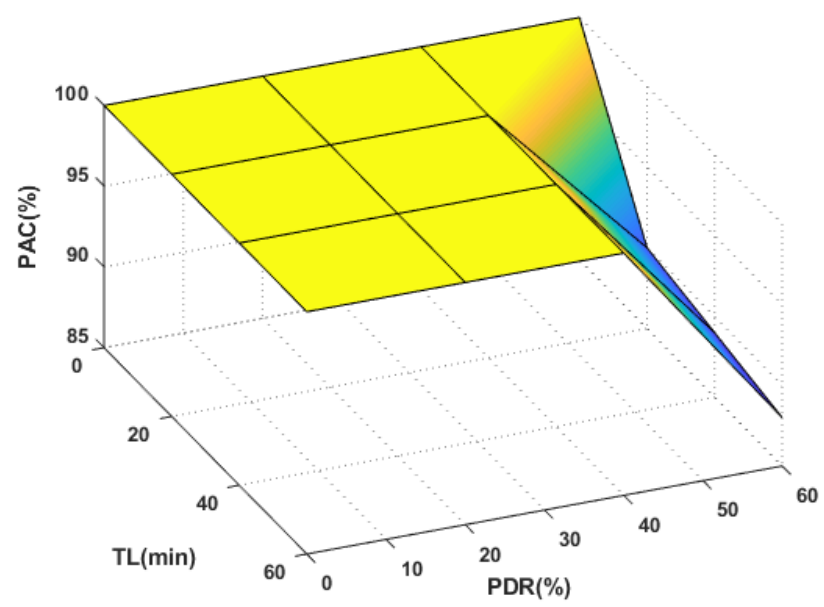

(b) Proposed Reward Method.

Fig. 3. Result of the Percentage of Average Comfortableness for 10 Residents System.

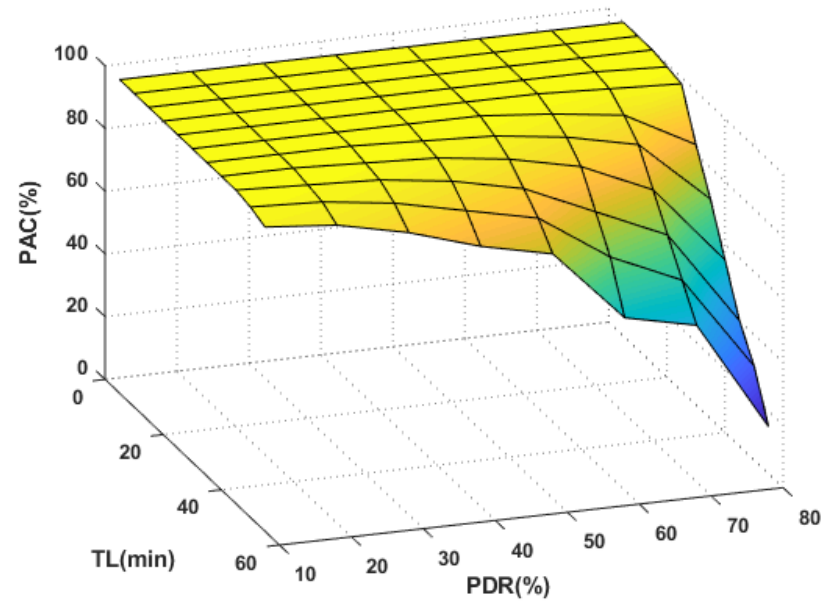

(a) Existing Method.

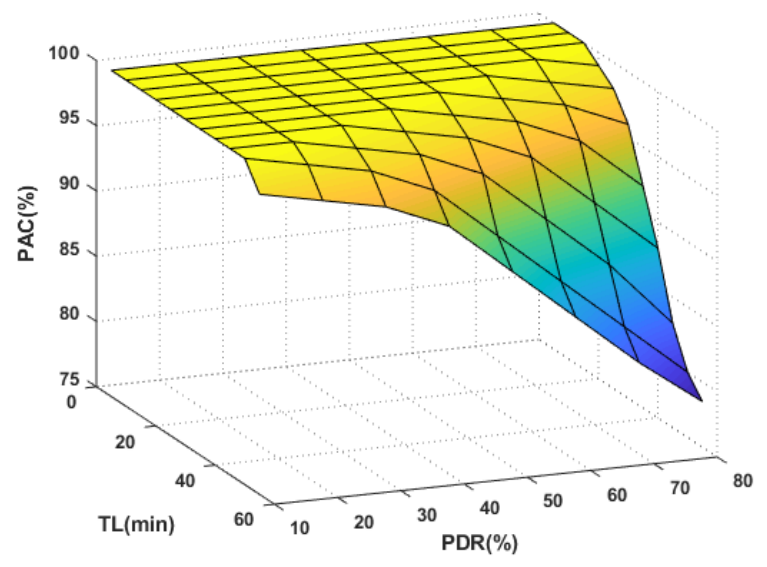

(b) Proposed Reward Method.

Fig. 4. Result of the Percentage of Average Comfortableness for 500 Resident Systems. 


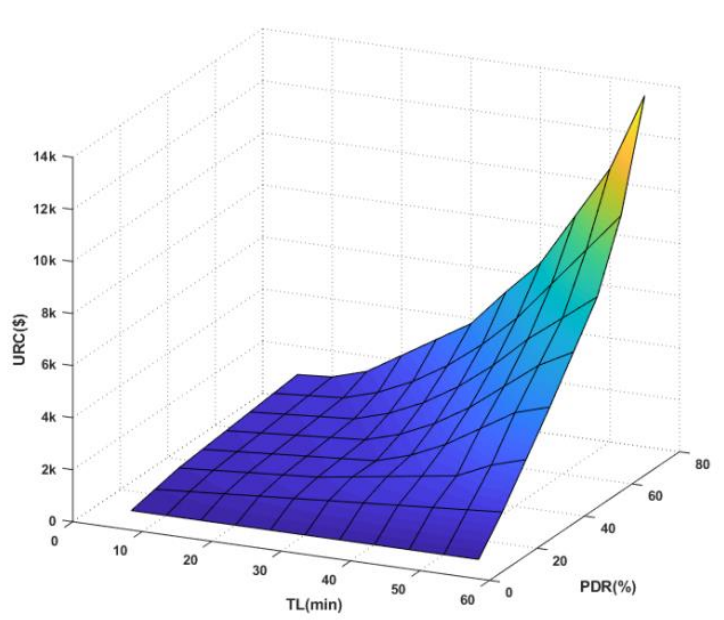

(a) Existing Method.

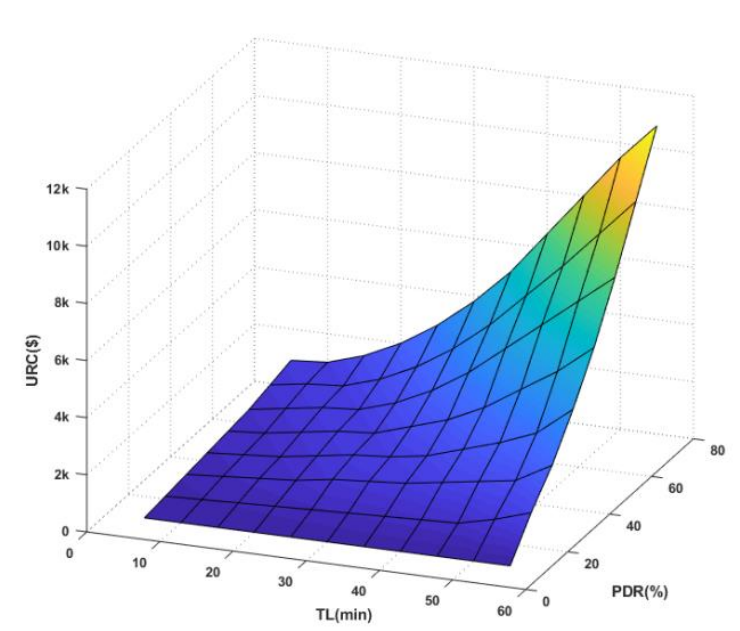

(b) Proposed Reward Method.

Fig. 5. Result of Utility Reward Cost for 500 Residents System.

TABLE VI. RESULT COMPARISON FOR 500 RESIDENTS

\begin{tabular}{|l|l|l|}
\hline Approach & $\begin{array}{l}\text { Percentage of average Comfort } \\
\text { (PAC) ( \%) }\end{array}$ & $\begin{array}{l}\text { Utility reward cost } \\
\text { (URC) (\$) }\end{array}$ \\
\hline Existing[2] & 19.5 & 13500 \\
\hline Proposed & 78.5 & 10700 \\
\hline
\end{tabular}

\section{CONCLUSIONS}

An efficient demand response program based on rewards is introduced in this paper. It takes into account all active electrical equipment involved in DR. In this analysis, the CI is the essential factor that defines the resident's level of comfort. This valid reward-based scheduling method minimizes utility reward cost and increases the PAC. It is identified that the proposed approach maintain the average comfort of consumer while increasing the residents from 10 to 500. Result of case studies inferred that the reward-based demand response program provides a better cost solution to utility and consumers compared to state of art work. In future, the proposed approach should be improved for meeting the realistic constraints that can be evaluated using large scale system with real time data.

\section{ACKNOWLEDGMENT}

The authors would like to express their thanks to Vellore Institute of Technology for their continuous support.

\section{REFERENCES}

[1] Yi Liu, Liye Xiao, Guodong Yao, and S.Q. Bu "Pricing-Based demand response for a smart home with various types of household appliances considering customer satisfaction" IEEE Access, vol.7,pp. 86463-86472, 2019.

[2] Q. Hu, F. Li, X. Fang, and L. Bai, "A framework of residential demand aggregation with financial incentives," IEEE Trans. Smart Grid, vol. 9, No. 1, pp. 497-505, Jan2018.

[3] E. Shahryari, H. Shayeghi, B. Mohammadi-ivatloo, M. Moradzadeh, "An improved incentive-based demand response program in day-ahead and intraday electricity markets" Energy 155 ,pp.205-214,2018.

[4] Valles M, Bello A, Renesas J, Frías P," Probabilistic characterization of electricity consumer responsiveness to economic incentives". Appl Energy ,Feb.2018.

[5] $\mathrm{Ni}, \mathrm{Z}$;; Das, A.A new incentive-based optimization scheme for residential community with financial trade-offs IEEE Access, Oct. 2018, 6, 57802-57813.

[6] M. R. Sarker, M. A. Ortega-Vazquez, and D. S. Kirschen, "Optimal coordination and scheduling of demand response via monetary incentives," IEEE Transactions on Smart Grid, vol. 6, no. 3, pp. 13411352, May 2015.

[7] Paudyal. P, Ni. Z, "Smart home energy optimization with incentives compensation from inconvenience for shifting electric appliances", Electrical Power and Energy Systems 109 (2019) 652-660.

[8] Mengmeng Yu, Seung Ho Hong "Incentive-based demand response considering hierarchical electricity market: A stagelberg game approach" Applied Energy 203 (2017) 267-279.

[9] C. Vivekananthan, Y. Mishra, G. Ledwich, and F. Li, "Demand response for residential appliances via customer reward scheme," IEEE Trans.Smart Grid, vol. 5, no. 2, pp. 809-820, Mar. 2014.

[10] Priti Paudyal, Prateek Munankarmi, Zhen Ni, Timothy M. Hansen, "A Hierarchical Control Framework with a Novel Bidding Scheme for Residential Community Energy Optimization" IEEE transaction on smart grid,2019.

[11] Sayyad N, Kazem Z, Behnam Mohammadi-Ivatloo, "Robust bidding and offering strategies of electricity retailer under multi-tariff pricing", Energy Economics 68 (2017) 359-372.

[12] S. Moon and J.-W. Lee, "Multi-residential demand response scheduling with multi-class appliances in smart grid," IEEE Trans. Smart Grid, vol. 9, no. 4, pp. 2518-2528, Jul. 2018.

[13] Joo, I.Y., Choi, D.H, "Optimal household appliance scheduling considering consumer's electricity bill target", IEEE Trans. Consum. Electron., 2017, 63,(1), pp. 19-27.

[14] Nan, S, Zhou, M, Li, G, "Optimal residential community demand response scheduling in smart grid", Applied Energy 210 (2018) 12801289.

[15] Sayyad Nojavan, Ramin Nourollahi, Hamed Pashaei-Didani, Kazem Zare, "Uncertainty-based electricity procurement by retailer using robust optimization approach in the presence of demand response exchange", Electrical Power and Energy Systems 105 (2019) 237-248.

[16] Shafie-Khah, M., Siano, P, "A stochastic home energy management system considering satisfaction cost and response fatigue', IEEE Trans. Ind. Inf., 2018, 14, (2), pp. 629-638.

[17] Z. Zhao, W. C. Lee, Y. Shin, and K.-B. Song, "An optimal power scheduling method for demand response in home energy management system,” IEEE Trans. Smart Grid, vol. 4, no. 3, pp. 1391-1400, Sep. 2013.

[18] M. Pipattanasomporn, M. Kuzlu, and S. Rahman, "An algorithm for intelligent home energy management and demand response analysis," IEEE Trans. Smart Grid, vol. 3, no.4, pp. 2166-2173, Dec. 2012.

[19] Beaudin, M., Zareipour, H, "Home energy management systems: a review of modelling and complexity", Renew. Sust. Energy Rev., 2015, 45, pp. 318-335. 
[20] F. Ruelens, B. J. Claessens, S. Vandael, B. D. Schutter, R. Babuska, and R. Belmans, "Residential demand response of thermostatically controlled loads using batch reinforcement learning," IEEE Trans. Smart Grid, vol. 8, no. 5, pp. 2149-2159, Sep. 2017.

[21] Shenglin Li, Junjie Yang, Wenzhan Song, and An Chen,“A Real-Time Electricity Scheduling for Residential Home Energy Management" IEEE Internet Of Things Journal, vol. 6, no. 2, Apr. 2019.pp.2602-2611.

[22] Muthuselvi G, Saravanan B, "Energy Consumption Scheduling Using Adaptive Differential Evolution Algorithm in Demand Response Programs", International Journal of intelligent engineering and systems (2019), vol. 12, no.5.
[23] K.Stenner, E.R.Frederiks, E.V.Hobman, and S.Cook, "Willingness to participate in direct load control: The role of consumer distrust", Applied Energy, vol. 189, pp.76-88, Mar. 2017.

[24] Seung-Jun Kim, Georgios B. Giannakis, "An online convex optimization approach to real-time energy pricing for demand response", IEEE Trans. Smart Grid 8,vol.6, pp.2784-2793, 2017.

[25] Yu Wang, Haiyang Lin, Yiling Liu, Qie Sun, Ronald Wennersten, "Management of household electricity consumption under price-based demand response scheme", Journal of Cleaner Production 204, 926$938,2018$.

\section{APPENDIX (NOMENCLATURE)}

\begin{tabular}{|c|c|}
\hline $\mathrm{H}-$ & Number of residents. \\
\hline $\mathrm{N}-$ & Number of appliances in a resident. \\
\hline$S_{E W H, h, t^{-}}$ & $\begin{array}{l}\text { Current state (ON/ OFF) of Electric Water Heater } \\
(\mathrm{EWH}) \text { in resident ' } h \text { ' at time } t \text {. }\end{array}$ \\
\hline$S_{E W H, h, t-1}$ & Previous state of EWH in resident ' $h$ ' \\
\hline$P_{E W H}-$ & Rated Power of EWH (kW) \\
\hline$p_{E W H, h, t}-$ & Power usage of EWH at resident ' $h$ ' at time $t(\mathrm{~kW})$ \\
\hline$T_{E W H, h, t}-$ & Current temperature of EWH $\left({ }^{\circ} \mathrm{F}\right)$ \\
\hline$T_{E W H, r^{-}}$ & Minimum required temperature of EWH $\left({ }^{\circ} \mathrm{F}\right)$ \\
\hline$S_{A C, h, t^{-}}$ & $\begin{array}{l}\text { Current state (ON / OFF) of Air Conditioner (AC) at } \\
\text { resident ' } h \text { ' at time t. }\end{array}$ \\
\hline$S_{A C, h, t-1}-$ & Previous State of Air Conditioner (AC) at resident ' $h$ ' \\
\hline$P_{A C^{-}}$ & Power rating of $\mathrm{AC}(\mathrm{kW})$ \\
\hline$p_{A C, h, t}-$ & Power usage of $\mathrm{AC}$ in resident ' $h$ ' at time't' $(\mathrm{kW})$ \\
\hline$T_{A C, h, t}-$ & Current temperature of $\mathrm{AC}$ in resident ' $\mathrm{h}$ ' at time ' $\mathrm{t}$ ' $\left({ }^{\circ} \mathrm{F}\right)$. \\
\hline$T_{A C, D B}-$ & Dead band temperature of $\mathrm{AC}\left({ }^{\circ} \mathrm{F}\right)$. \\
\hline$T_{A C, s p}-$ & Setpoint temperature of $\mathrm{AC}\left({ }^{\circ} \mathrm{F}\right)$ \\
\hline$S_{C D, h, t^{-}}$ & $\begin{array}{l}\text { Current state (ON / OFF) of Clothes Dryer (CD) in } \\
\text { resident ' } h \text { ' at time t. }\end{array}$ \\
\hline$T_{\mathrm{CD}, a c c}-$ & Accumulated $\mathrm{ON}$ time temperature of $\mathrm{CD}\left({ }^{\circ} \mathrm{F}\right)$. \\
\hline$T_{\mathrm{CD}, r}-$ & Required $\mathrm{ON}$ time temperature of $\mathrm{CD}\left({ }^{\circ} \mathrm{F}\right)$. \\
\hline$p_{\mathrm{CD}, h, t}{ }^{-}$ & Power consumption of CD at resident ' $h$ ' at time $t(k W)$. \\
\hline$P_{C D^{-}}$ & Power rating of $\mathrm{CD}(\mathrm{kW})$. \\
\hline$P_{\mathrm{EV}}{ }^{-}$ & Power rating of EV $(\mathrm{kW})$. \\
\hline$S_{E V, h, t}-$ & $\begin{array}{l}\text { ON-OFF status of Electric Vehicle }(E V) \text { in resident ' } h \text { ' at } \\
\text { time t. }\end{array}$ \\
\hline$p_{\mathrm{EV}, h, t}-$ & Power charge of EV in resident ' $h$ ' at time $t(\mathrm{~kW})$. \\
\hline$R W R_{h, t}-$ & Reward rate of resident ' $h$ ' at time $t$. \\
\hline$S O C_{h, t}-$ & $\begin{array}{l}\text { Battery charging state of resident ' } h \text { ' during time period } t \\
(\%) \text {. }\end{array}$ \\
\hline$S O C_{\max }-$ & EV-Maximum charging rate of the battery $(\%)$. \\
\hline
\end{tabular}

$S_{D W, t^{-}}$

$P_{D w}-$

$p_{D W, h, t}-$

$T_{D W, i, t}-$

$T_{D W, s^{-}}$

$S_{C W, h, t}{ }^{-}$

$P_{C W}-$

$p_{C W, h, t}{ }^{-}$

$T_{C W, h, t}-$

$T_{C W, S^{-}}$

$S_{P P, h, t}-$

$P_{P P}-$

$p_{P P, h, t}-$

$T_{P P, h, t}-$

$T_{P P, S}-$

$T_{L o, h}$

$T_{H i, h}{ }^{-}$

$T_{R M, h}-$

$P_{T, h, t}-$

$P_{h, n, t}$

$P_{a, h, t}-$

PDRR -
ON-OFF status of Dish Washer (DW) in resident ' $h$ ' at time $\mathrm{t}$.

Power rating of DW $(\mathrm{kW})$.

Power usage of DW in resident ' $h$ ' at time $t(\mathrm{~kW})$.

Current temperature of DW $\left({ }^{\circ} \mathrm{F}\right)$.

Setpoint temperature of DW $\left({ }^{\circ} \mathrm{F}\right)$.

ON-OFF status of Cloth Washer (CW) heater in resident 'h' at time't.'

Power rating of $\mathrm{CW}(\mathrm{kW})$.

Power usage of $\mathrm{CW}$ in resident ' $\mathrm{h}$ ' at time' $\mathrm{t}$ ' $(\mathrm{kW})$.

Current temperature of $\mathrm{CW}\left({ }^{\circ} \mathrm{F}\right)$.

Setpoint temperature of $\mathrm{CW}\left({ }^{\circ} \mathrm{F}\right)$.

ON-OFF status of Pool Pump (PP) at resident ' $h$ ' at time't'.

Power rating of $\mathrm{PP}(\mathrm{kW})$.

Power usage of PP in resident ' $h$ ' at time $t(\mathrm{~kW})$.

Current temperature of $\mathrm{PP}\left({ }^{\circ} \mathrm{F}\right)$ of resident ' $h$ ' at time t.

Setpoint temperature of PP $\left({ }^{\circ} \mathrm{F}\right)$.

Minimum temperature of the room in resident ' $h$ ' $\left({ }^{\circ} \mathrm{F}\right)$.

Maximum temperature of the room in resident ' $h$ ' $\left({ }^{\circ} \mathrm{F}\right)$.

Room temperature of resident ' $h$ ' $\left({ }^{\circ} \mathrm{F}\right)$.

Overall power usage of resident ' $h$ ' at the time' $t$ '.

Power usage of appliance ' $n$ ' of resident ' $h$ ' at the time ' $t$ '.

Actual Power consumption of resident ' $h$ ' at time ' $t$ '.

Preferred Demand Reduction Request 